\title{
Performance Modification of Asphalt Binders using Thermoplastic Polymers
}

\author{
H. I. Al-Abdul Wahhab* and I. Abaker \\ Civil Engineering Department, KFUPM, Dhahran 31261,Saudi Arabia
}

Received 18 June 2003; accepted 11 October 2003

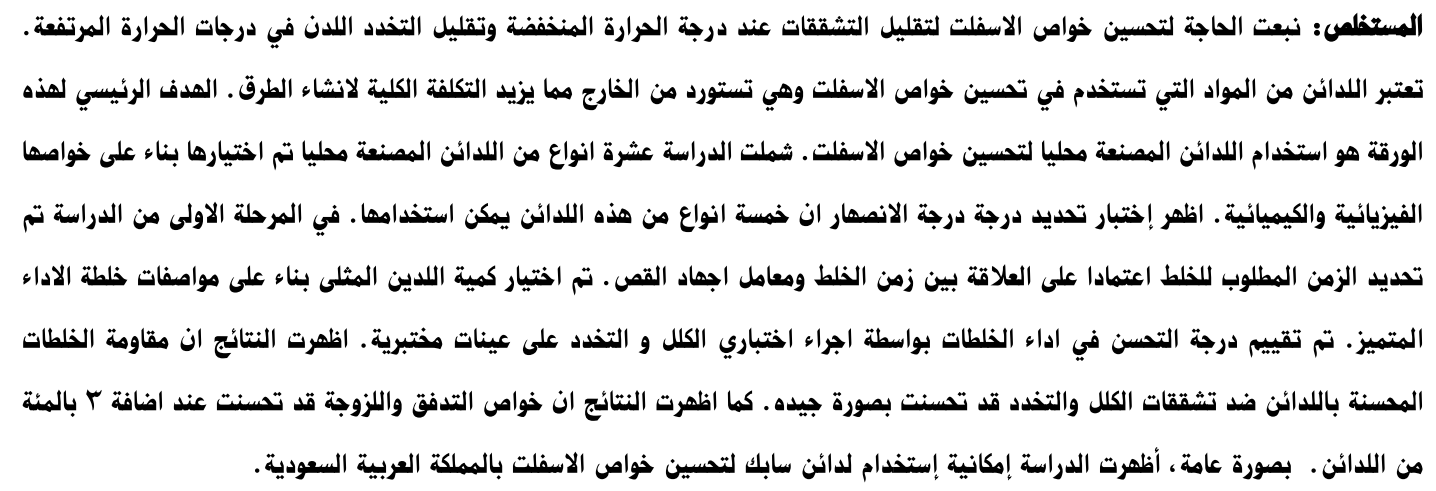

الهغردات الهنتامية: اللدائن ، الاسفلت المتميز، تشققات، التخدد اللدن، الطرق.

\begin{abstract}
There is a need to improve the performance of asphalt binders to minimize stress cracking that occurs at low temperatures and plastic deformation at high temperatures. Importation of used asphalt-polymers from abroad, leads to an increase in the total construction cost as compared to the cost if the used polymers were of local origin. The main objective of this research was to modify locally produced asphalt. Ten polymers were identified as potential asphalt modifiers based on their physical properties and chemical composition. After preliminary laboratory evaluation for the melting point of these polymers, five polymers were selected for local asphalt modification. In the initial stage, required mixing time was decided based on the relation between shear loss modulus and mixing time. The optimum polymer content was selected based on Superpave binder performance grade specifications. The suitability of improvement was verified through the evaluation of permanent deformation and fatigue behavior of laboratory prepared asphalt concrete mixes. The results indicated that the rheological properties of the modified binders improved significantly with sufficient polymer content (3\%). The aging properties of the modified binders were found to be dependent on the type of polymer. The fatigue life and resistance to permanent deformation were significantly improved due to enhanced binder rheological properties. Thus, local asphalts can be modified using thermoplastic polymers.
\end{abstract}

Keywords: Polymers, Modified asphalt, Fatigue cracking, Rutting, Roads

\section{Introduction}

The use of polymer-modified asphalt (PMA) to achieve better asphalt pavement performance has been observed for a long time (Al-Abdul Wahhab and Al-Amri, 1991; Bouldin et al., 1991; Sartori et al., 1996; Baig and AlAbdul Wahhab, 1998). The properties of PMA are depend ent on the polymer characteristics and content, and bitu-

*Corresponding author E-mail: hawahab@kfupm.edu.sa men nature as well as the blending process. Despite the large number of polymeric products, there are relatively few types that are suitable for bitumen modification. When used as modifiers, polymers should be compatible with bitumen, be capable of being processed by conventional mixing and laying equipment, and be able to maintain their premium properties during mixing storage and application in service. The use of a modifier should also be cost-effective. Two classes of polymers are typically used in asphalt modification; elastomers and plastomers. The 
relative usefulness of these polymers can vary widely.

The concept of modifying asphalt binders and mixtures is not new. Many researchers have studied the effects of mineral fillers on the behavior of asphalt (Al-Abdul Wahhab and Al-Amri, 1991; Bouldin et al., 1991; Sartori et al., 1996; Baig and Al-Abdul Wahhab, 1998). Another early method of asphalt modification consisted of mixing two or more asphalt binders of different paving grades or sources. This technique has continued through the years and often delivers a satisfactory product. One major problem, however, is that sometimes the two asphalts are not chemically compatible with each other. Compatibility cannot be predicted effectively. This leads to premature pavement distress (Anderton, 1991).

For the past two decades, significant research has been conducted on PMA mixtures. Polymers can successfully improve the performance of asphalt pavements at low, moderate and high temperatures by increasing mixture resistance to fatigue cracking, thermal cracking and permanent deformation. It was found that the rheological and engineering properties of PMA mixtures largely depend on the polymer type and content. The improvement in fatigue life and resistance to permanent deformation is mainly due to the improvement in the rheological properties of the binders (Khattak and Baladi, 2001). When an asphalt binder is subjected to cyclic load or stress, the material response to tension and compression consists of three major components: elastic, viscoelastic and plastic. The compression plastic behavior, i.e. permanent strain, is responsible for permanent deformation and consequently results in pavement rutting.

In most cases, it has been found that the structure of the pure modified binder is completely different from the structure of the polymer in the asphalt-aggregate mixture (Wegan and Brule, 1999). When a continuous network of the polymer phase could be detected in the binder, no continuous network of the polymer phase could be detected in the asphalt-aggregate mixture. This is the case with 7\% ethylene vinyl acetate (EVA) or styrene butadiene styrene (SBS) modified binders. However, for low polymer content (e.g.3\%), the same structure of the polymer phase in the binder and in the asphalt-aggregate mixtures was reported. EVA seems to have an affinity for the aggregate surface. If the EVA phase, swollen by a part of the maltenes, has a higher solubility parameter compared to the asphalt phase, then the EVA phase will, at equilibrium, surround the aggregate with its many polar groups.

The compatibility and storage stability of polymermodified bitumen (PMB) were shown to be largely dependent on polymer content and were influenced by the characteristics of base bitumens and polymers. Polymer modification increased the elastic responses and dynamic modulus of bitumens at intermediate and high temperatures. It also reduced the temperature susceptibility and glass transition, and limiting stiffness temperatures of the bitumens. The degree of the improvement generally increases with polymer content, but varies with bitumen source/grade and polymer type (Isacsson and Lu, 1999).

The Strategic Highway Research Program (SHRP) conducted a seven-year \$50-million asphalt research and developed study on performance-based specifications for asphalt binder that were intended to replace the present penetration and viscosity graded asphalt specifications (Harrigan et al., 1994). The program yielded a set of tests to measure asphalt binder properties at high, intermediate and low temperatures, and for fresh and aged conditions. These tests were intended to represent eight to ten years of pavement service. Similar work was carried out to adapt SHRP binder performance specifications for the Arabian Gulf countries (GC) (Al-Abdul Wahhab et al., 1996). In this work, the GC region was divided into different temperature zones and the required asphalt performance grade (PG) for each zone was specified. They concluded that the asphalt cement as used locally is only suitable for about 40 percent of the GC area. They found that the required asphalt binder ranged between PG 64-10 and PG 76-10. It was shown that different modification procedures (ranging from air blowing to polymer modification) need to be performed for different asphalt binders.

Imported polymers are used to improve local asphalt concrete mixes in many countries. Off-spec polymers, which are considered industrial wastes, are sold at minimal cost. These polymers, if proved effective for asphalt modification, could lead to a significant reduction in construction cost.

The main objective of the present research was to characterize and test the properties of modified bitumens containing thermoplastic polymers. This was achieved through the evaluation of permanent deformation and fatigue behavior of laboratory prepared asphalt mixes. The factors affecting modification were also evaluated. Moreover, this study aims at improving asphalt mixes by modifying locally produced asphalts with polymer.

\section{Experimental Set-Up And Procedure}

This study consisted of two phases; the first phase dealt with the collection of asphalt from Riyadh (RY) and Ras Tanura (RT) refineries, and polymers from Saudi Basic Industries Company (SABIC)-The use of local polymers to modify local asphalts was evaluated based on superpave binder performance specifications. In the second phase, polymer-modified asphalts were used in a hot asphalt concrete mixture (HACM) and tested for resistance to fatigue, to permanent deformation and to environmental effects, Figure 1.

\subsection{Materials}

Ten different grade polymers were used in this study. These were placed into six main groups; linear low density polyethylene, high density polyethylene, low density polyethylene, medium density polyethylene, polypropylene and styrenic heavy waste, Table 1.The coarse and fine 


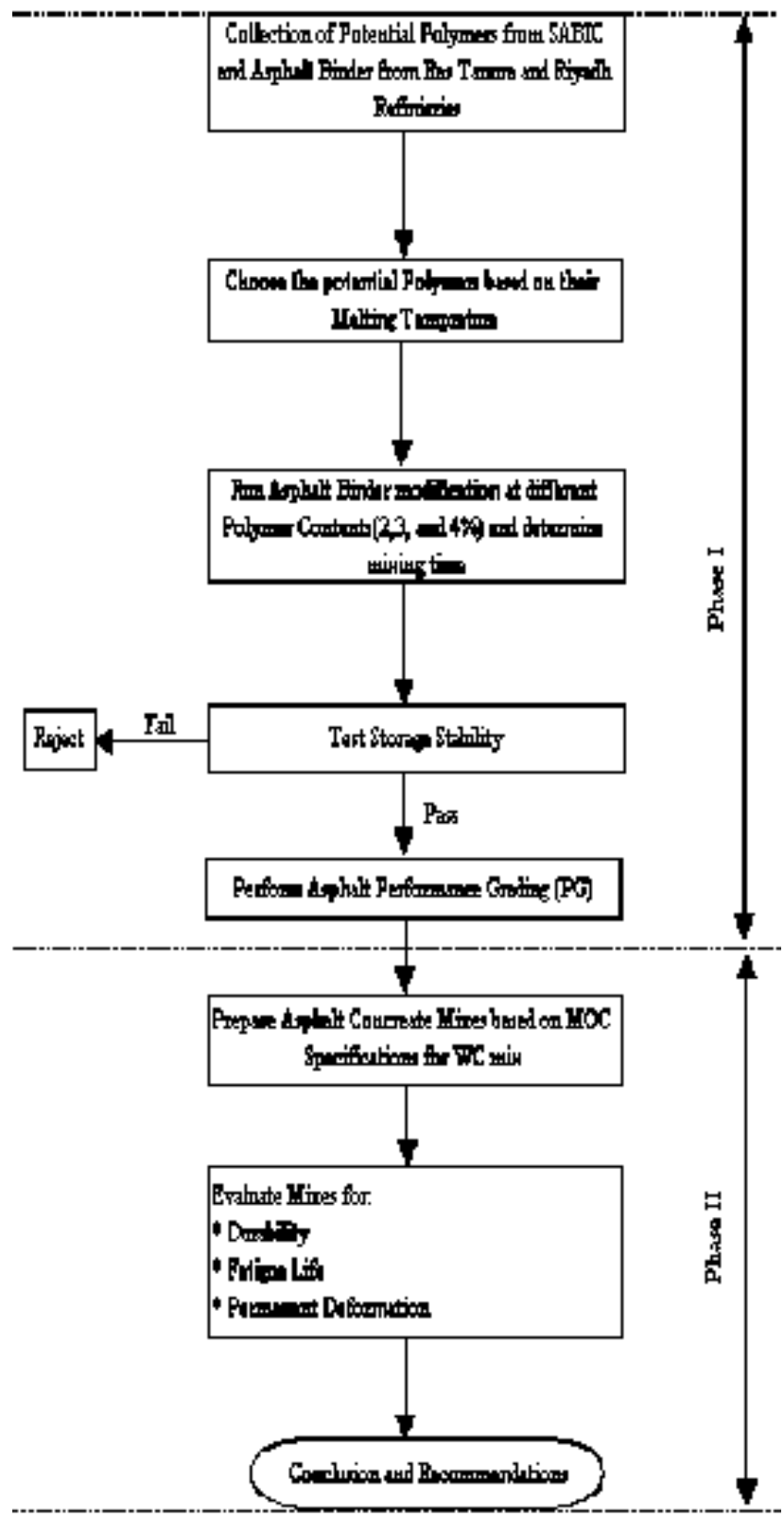

Figure 1. Schematic flow chart for work procedure

Table 1. List of selected polymers

SN

\section{Commercial Name}

1 High Density Polyethylene (HDPE)

2 Linear Low Density Polyethylene (LLDPE)

3 Polypropylene (PP)

4 Low Density Polyethylene (LDPE)

5 Linear Low Density Polyethylene

$$
\text { (LLDPE) }
$$

6 Medium Density Polyethylene (MDPE)

7 Linear Low Density Polyethylene

$$
\text { (LLDPE) }
$$

8 High Density Polyethy lene (HDPE)

9 High Density Polyethylene (HDPE -II)

10 Styrenic Heavy Waste (SHW)

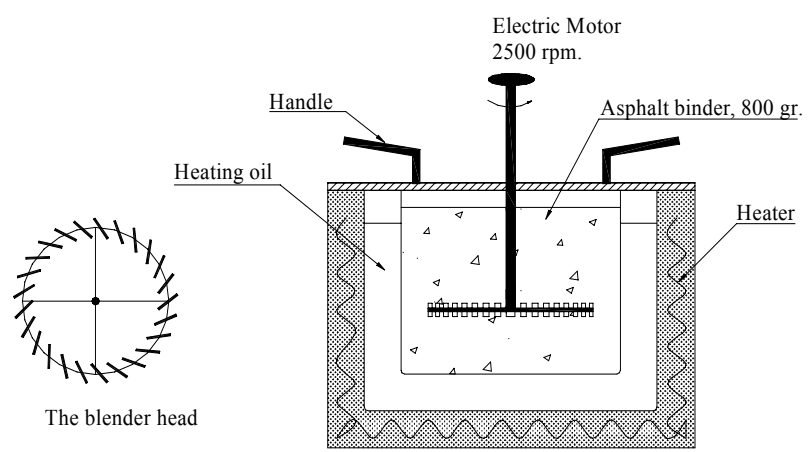

Figure 2. Schematic diagram for blending machine

aggregates used in the asphalt mixture were obtained from Abu-Hadriyah, Eastern Province of Saudi Arabia.

\subsection{Identification of potential polymers}

The first phase of the modification work focused on the identification of potential polymers. The cited literature coupled with manufacturer recommendations and melting temperatures were used to identify the tentative polymer concentrations, blending times and blending temperature. Based on the melting temperatures, P5, P6, P7, P8, and P9 were found to be suitable for blending with asphalt. Polymers that had a melting temperature of more than $180^{\circ} \mathrm{C}$ were rejected.

Polymers were blended with the asphalt from the refineries. The blending temperature was determined based on the melting temperature of the polymers. The selected blending temperature was made equal to the melting temperature plus $5^{\circ} \mathrm{C}$ in order to ensure good dispersion of polymers. A special blender was assembled, consisting of a high shear blade, a heated oil bath, and a direct current (DC) motor capable of producing up to $2500 \mathrm{rev}-$ olutions per minute (RPM), Figure 2. Each polymer type was blended with $800 \mathrm{gm}$ of asphalt binder to produce the polymer-modified asphalt binder. The quantities of each polymer were fixed at 3,4 , and $5 \%$ by weight of the binder.

The optimum polymer content was selected based on the evaluation of different percentages of the polymerasphalt binder blends through their improvements in the performance grade. The third parameter determined was the storage stability of the blends. Two major factors were evaluated in this test: The effect of extended storage at high temperature in the range of 160 to $180^{\circ} \mathrm{C}$, and the effect of mechanical agitation of the modified binders.

The test procedure was conducted at $160^{\circ} \mathrm{C}$ for 72 hours. The agitation speed was fixed at $500 \mathrm{rpm}$. The criterion for determining the storage stability was based on conducting dynamic shear rheometer (DSR) at high temperature of pavement design as recommended by Bahia et al. (2001). In addition, rotational viscosity (RV) was added as a new measurement for storage stability to ensure adequate pump-ability of the binder. The ratio of separation under agitation conditions was calculated. The binder was 


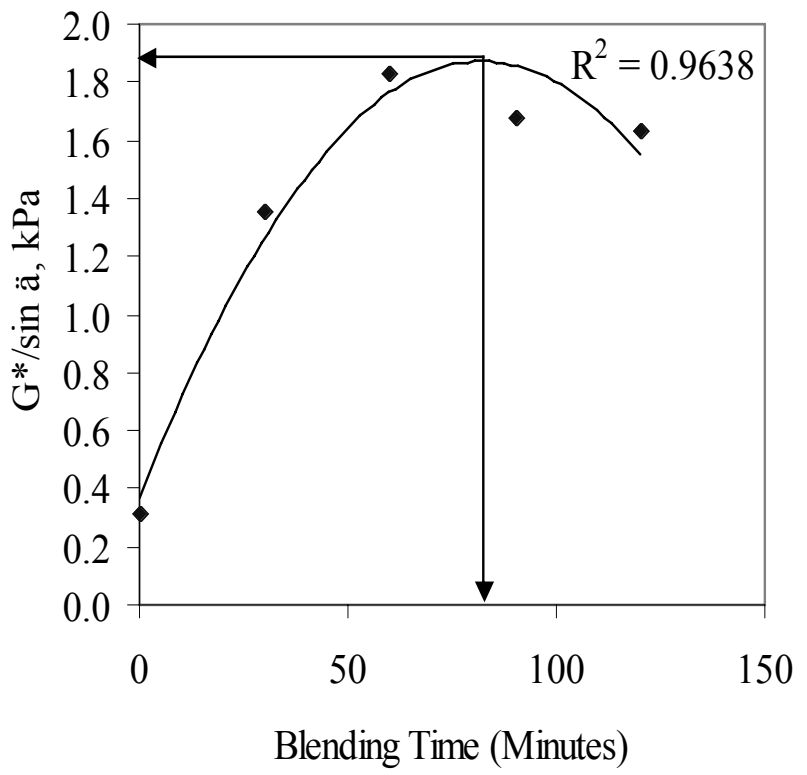

Figure 3. Determination of optimum blending time of RY with P5-4\%

considered stable if the percent loss in RV and $\mathrm{G}^{*} / \sin \delta$ was less than $20 \%$.

\subsection{Sample testing}

Optimum blending time was determined by means of the parameter, $G^{*} / \sin \delta$ at $76^{\circ} \mathrm{C}\left(G^{*}=\right.$ Shear modulus; $\delta=$ Phase angle). The $G^{*} / \sin \delta$ was evaluated during the blending process at an interval of 30 minutes. The maximum blending time was assumed to be two hours. The storage stability of the PMA for various polymers was evaluated by simulating the actual storage conditions in the field. The storage temperature was $160^{\circ} \mathrm{C}$ and stirred at a speed of 200 RPM. The storage time was fixed to be three days. Samples were taken from the top and bottom portion of the storage container at an interval of 24 hours. $G^{*} / \sin \delta$ at $76^{\circ} \mathrm{C}$ were measured to identify the storage stability and the maximum possible storage time. Based on the SHRP binder performance specifications, the final performance grade was determined for the RY and RT asphalt modified with selected polymers. The polymer content was fixed at three levels $(2 \%, 3 \%$, and $4 \%)$. Asphalt concrete mix was designed following Marshall mix design in accordance with the MOC specifications. The optimum asphalt content obtained for wearing course was used to prepare control mixes and polymer-modified asphalt concrete specimens. The standard Marshall specimens of 100 $\mathrm{mm} \times 62.5 \mathrm{~mm}$ were prepared for each polymer and control mix.

Table 2. Measured stored stability

\begin{tabular}{|c|c|c|c|c|c|c|c|}
\hline \multicolumn{2}{|c|}{ Asphalt Type } & \multicolumn{3}{|c|}{ RY } & \multicolumn{3}{|c|}{ RT } \\
\hline \multirow{2}{*}{ Polymer Type } & \multirow{2}{*}{ Time (hr) } & \multicolumn{2}{|c|}{$G^{*} / \sin$ ä kPa } & \multirow{2}{*}{ Loss \% } & \multicolumn{2}{|c|}{$G^{*} / \sin$ ä kPa } & \multirow{2}{*}{ Loss \% } \\
\hline & & Top & Bottom & & Top & Bottom & \\
\hline \multirow{5}{*}{ P5-3\% } & 0 & 1.635 & 1.635 & 0.0 & 1.425 & 1.425 & 0.0 \\
\hline & 24 & 1.896 & 2.016 & 6.0 & 1.623 & 1.803 & 10.0 \\
\hline & 48 & 2.543 & 2.896 & 12.2 & 2.171 & 2.236 & 2.9 \\
\hline & 72 & 3.177 & 3.786 & 16.1 & 2.526 & 2.674 & 5.5 \\
\hline & $\mathrm{RV}$ after $72 \mathrm{~h}$ & 2436 & 2596 & 6.2 & 2037 & 2062 & 1.2 \\
\hline \multirow{5}{*}{ P6-3\% } & 0 & 1.241 & 1.241 & 0.0 & 1.108 & 1.108 & 1.1 \\
\hline & 24 & 1.203 & 1.256 & 4.2 & 1.101 & 1.139 & 3.4 \\
\hline & 48 & 1.288 & 1.378 & 6.5 & 1.212 & 1.292 & 6.7 \\
\hline & 72 & 1.639 & 1.811 & 9.5 & 1.547 & 1.635 & 5.4 \\
\hline & $\mathrm{RV}$ after $72 \mathrm{~h}$ & 2768 & 2808 & 1.4 & 2237 & 2250 & 0.6 \\
\hline \multirow{5}{*}{ P7-3\% } & 0 & 1.381 & 1.381 & 0.0 & 1.337 & 1.337 & 0.0 \\
\hline & 24 & 1.750 & 2.011 & 14.8 & 2.942 & 3.024 & 2.7 \\
\hline & 48 & 4.490 & 7.626 & 69.8 & 3.154 & 19.229 & 83.6 \\
\hline & 72 & 8.109 & 13.776 & 69.9 & 5.648 & 21.331 & 73.5 \\
\hline & $\mathrm{RV}$ after $72 \mathrm{~h}$ & 3202 & 5732 & 79.0 & 3737 & 6062 & 38.4 \\
\hline \multirow{5}{*}{ P8-3\% } & 0 & 1.219 & 1.219 & 0.0 & 1.081 & 1.081 & 0.0 \\
\hline & 24 & 1.55 & 1.568 & 1.1 & 1.123 & 1.155 & 2.8 \\
\hline & 48 & 2.455 & 2.517 & 2.5 & 2.235 & 2.271 & 1.6 \\
\hline & 72 & 3.678 & 3.987 & 7.8 & 4.477 & 4.742 & 5.6 \\
\hline & $\mathrm{RV}$ after $72 \mathrm{~h}$ & 2635 & 2799 & 5.9 & 2485 & 2490 & 0.2 \\
\hline \multirow{5}{*}{ P9-3\% } & 0 & 1.191 & 1.191 & 0.0 & 1.056 & 1.056 & 0.0 \\
\hline & 24 & 1.973 & 2.011 & 1.9 & 1.602 & 1.861 & 13.9 \\
\hline & 48 & 2.513 & 2.713 & 7.4 & 2.713 & 2.927 & 7.3 \\
\hline & 72 & 3.149 & 3.5 & 10.0 & 3.164 & 3.497 & 9.5 \\
\hline & RV after $72 \mathrm{~h}$ & 3210 & 3350 & 4.2 & 2795 & 2850 & 1.9 \\
\hline
\end{tabular}

$\mathrm{RV}=$ Rotational Viscosity 
Table 3. Performance grade of different polymers

\begin{tabular}{cccc}
\hline \multicolumn{1}{c}{ Asphalt Type } & & RY & RT \\
\cline { 1 - 2 } Polymer & $\begin{array}{c}\text { Polymer } \\
\text { Content } \\
\text { (\%) }\end{array}$ & & \\
\cline { 1 - 2 } $\begin{array}{c}\text { Zero- } \\
\text { Polymer }\end{array}$ & 0 & PG 70-10 & PG 64-22 \\
P5 & 2 & PG 70-22 & PG 70-22 \\
& 3 & PG 76-16 & PG 76-10 \\
& 4 & PG 82-10 & PG 76-10 \\
P6 & 2 & PG 76-22 & PG 70-22 \\
& 3 & PG 76-16 & PG 76-16 \\
& 4 & PG 76-10 & PG 76-10 \\
P8 & 2 & PG 76-22 & PG 70-22 \\
& 3 & PG 76-22 & PG 76-10 \\
& 4 & PG 82-16 & PG 76-10 \\
& 2 & PG 76-16 & PG 70-22 \\
P9 & 3 & PG 76-10 & PG 76-10 \\
& 4 & NA & PG 76-10 \\
\hline
\end{tabular}

The following tests were carried out in order to fully evaluate the polymer-modified mixes and to compare with the control mix: Lottman test for moisture susceptibility (AASHTO T-283-89), Resilient modulus test (ASTM D 4123), Fatigue test and Permanent deformation (rutting test)

\section{Results and Discussion}

\subsection{Blending time, storage stability and perform- ance grade}

Figure 3 shows the variation of $G^{*} / \sin \delta$ modified by $4 \%$ P5 polymer with blending time. Table 2 shows the final results for different types of polymers. The stable blends that passed storage condition were P5, P6, P8, and P9. The stable state was determined based on the differ-

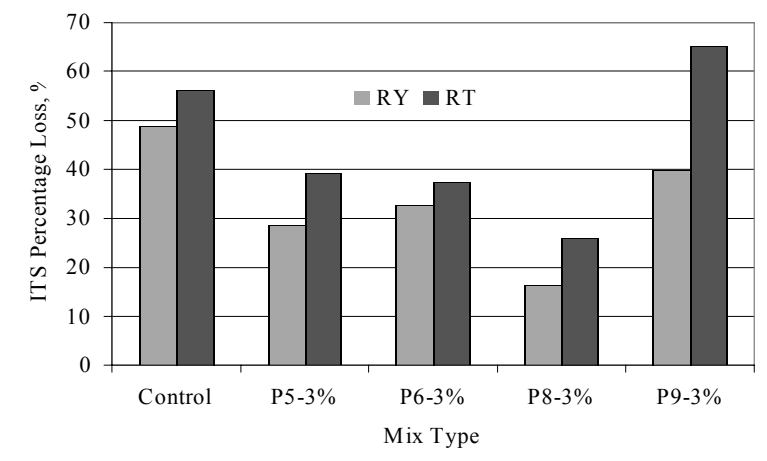

Figure 4. Lottman test results ence between the value of $G^{*} / \sin \delta$ at the top and the bottom of the storage container. It was assumed that the sample was stable if the difference was less than or equal to $20 \%$. From this assumption it was clear that P7 had a higher separation potential when blended with two type of asphalt. Therefore, it was rejected. In general, all asphalt polymer blends after storage exhibited an increase in $G^{*}$ (top or bottom) in comparison to the freshly tested blend (unstored). This may be attributed partially to an increase in the molecular association between the polymer and the asphalt binder and partially to the aging of asphalt due to prolonged storing. The rotational viscosity (RV) increased with storage time. This increase in viscosity may limit the storage time so as to reduce the possibility of getting very stiff asphalt. The rotational viscosity should not be more than 3,000 cp. It was found that the RV of P5, P6, and P8 blends were still within the limit after 72-hour storage. The RV of P9, however, exceeded $3000 \mathrm{cp}$. This indicated that a blend with P9 cannot be stored for more than 48 hours.

The results of $\mathrm{PG}$ in Table 3 showed that polymer types P5, P6, P8 and P9 satisfied the PG binders performance requirements with percentage of $3 \%, 2 \%, 2 \%$ and $2 \%$ respectively, when blended with RY asphalt. They also satisfied the PG binder specification with percentage of $3 \%$ when blended with RT asphalt. It was noticeable that an increase in polymer content caused an increase in creep stiffness and a decrease in $m$-value. It appeared that a

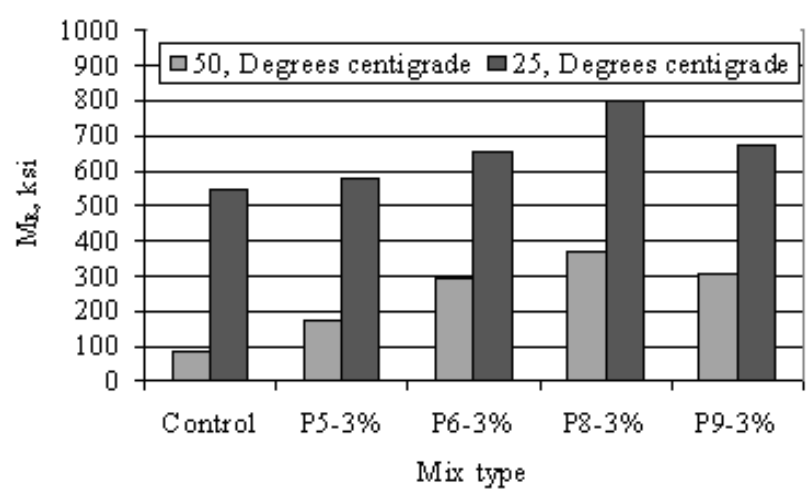

Figure 5. Comparison of $M_{R}(k s i)$ at $50^{\circ} \mathrm{C}$ and $2^{\circ} \mathrm{C}$ for $\mathrm{RY}$

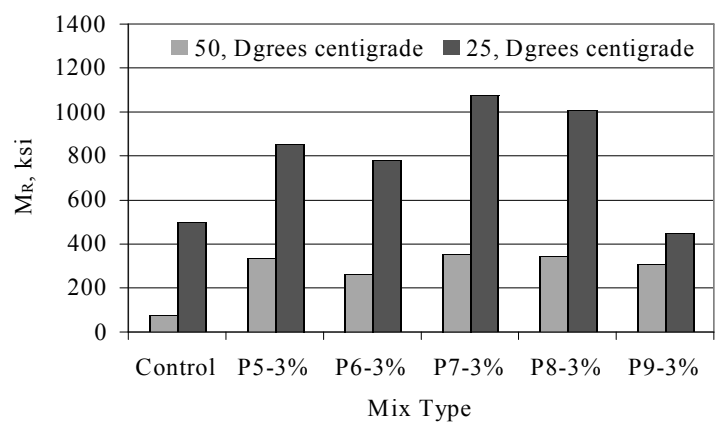

Figure 6. Comparison of $M_{R}$ (ksi) at $50^{\circ} \mathrm{C}$ and $2^{\circ} \mathrm{C}$ for $\mathrm{RT}$ 
Table 4. I.T.S. test results

\begin{tabular}{|c|c|c|c|c|c|c|c|}
\hline \multirow{2}{*}{$\begin{array}{c}\text { Asphalt } \\
\text { Type }\end{array}$} & \multirow{2}{*}{$\begin{array}{l}\text { Polymer } \\
\text { Type }\end{array}$} & \multirow{2}{*}{$\begin{array}{l}\text { Condition } \\
\text { (I.T.S.) }\end{array}$} & \multicolumn{3}{|c|}{ Sample No. } & \multirow{2}{*}{ Average } & \multirow{2}{*}{ Loss \% } \\
\hline & & & 1 & 2 & 3 & & \\
\hline \multirow{10}{*}{ RY } & \multirow{2}{*}{ Control } & Initial & 11.10 & 10.42 & 9.23 & 10.25 & \multirow{2}{*}{48.80} \\
\hline & & Final & 5.51 & 4.98 & 5.26 & 5.25 & \\
\hline & \multirow{2}{*}{ P5-3\% } & Initial & 15.51 & 16.20 & 15.28 & 15.66 & \multirow{2}{*}{28.60} \\
\hline & & Final & 9.75 & 10.35 & 13.45 & 11.18 & \\
\hline & \multirow{2}{*}{ P6-3\% } & Initial & 16.00 & 15.60 & 14.20 & 15.27 & \multirow{2}{*}{32.70} \\
\hline & & Final & 11.20 & 10.45 & 9.16 & 10.27 & \\
\hline & \multirow{2}{*}{ P8-3\% } & Initial & 13.52 & 12.65 & 12.68 & 12.95 & \multirow{2}{*}{16.30} \\
\hline & & Final & 10.31 & 11.42 & 10.80 & 10.84 & \\
\hline & \multirow{2}{*}{ P9-3\% } & Initial & 13.56 & 14.17 & 13.21 & 13.65 & \multirow{2}{*}{39.90} \\
\hline & & Final & 8.52 & 7.77 & 8.32 & 8.20 & \\
\hline \multirow{10}{*}{ RT } & \multirow{2}{*}{ Control } & Initial & 10.00 & 9.12 & 8.37 & 9.16 & \multirow{2}{*}{56.17} \\
\hline & & Final & 3.23 & 4.05 & 4.77 & 4.02 & \\
\hline & \multirow{2}{*}{ P5-3\% } & Initial & 18.51 & 18.01 & 15.28 & 17.27 & \multirow{2}{*}{39.15} \\
\hline & & Final & 8.72 & 9.35 & 13.45 & 10.51 & \\
\hline & \multirow{2}{*}{ P6-3\% } & Initial & 14.99 & 14.76 & 13.16 & 14.30 & \multirow{2}{*}{37.31} \\
\hline & & Final & 8.26 & 10.45 & 8.19 & 8.97 & \\
\hline & \multirow{2}{*}{ P8-3\% } & Initial & 13.28 & 11.65 & 12.31 & 12.41 & \multirow{2}{*}{25.89} \\
\hline & & Final & 8.31 & 11.42 & 7.87 & 9.20 & \\
\hline & \multirow{2}{*}{ P9-3\% } & Initial & 13.56 & 15.17 & 14.16 & 14.30 & \multirow{2}{*}{65.12} \\
\hline & & Final & 5.81 & 4.87 & 4.28 & 4.99 & \\
\hline
\end{tabular}

Table 5. Resilient modulus (ksi)

\begin{tabular}{crrrr} 
Mix & \multicolumn{2}{c}{ RY } & \multicolumn{2}{c}{ RT } \\
Type & \multicolumn{2}{c}{ Temperature } & \multicolumn{2}{c}{ Temperature } \\
& $\mathbf{5 0}^{\circ} \mathbf{C}$ & $\mathbf{2 5}^{\circ} \mathbf{C}$ & $\mathbf{5 0}^{\circ} \mathbf{C}$ & $\mathbf{2 5}^{\circ} \mathbf{C}$ \\
Control & 85.0 & 547.3 & 76.5 & 497.3 \\
P5-3\% & 171.9 & 576.4 & 335.2 & 850.1 \\
P6-3\% & 293.6 & 654.2 & 258.5 & 780.8 \\
P8-3\% & 369.3 & 799.8 & 344.6 & 1005.3 \\
P9-3\% & 305.6 & 671.7 & 305.6 & 447.5
\end{tabular}

higher polymer content reduced the resistance against low temperature cracking.

\subsection{Asphalt concrete mix evaluation}

Water sensitivity test (Lottman test AASHTO T-283-89): This test was carried out in order to find the moisture susceptibility (stripping resistance) of modified and control mixes using indirect tensile strength (ITS). Table 4 and Figure 4 show the percent loss in the indirect tensile strength after Lottman conditioning of the samples. The results obtained indicate that the average percent loss in strength due to moisture damage is effectively reduced in P8 modified asphalt concrete mix. The percent loss in P5, P6, and P9 are less than the percent loss in the control mix but still they are higher than the recommended limit based on Superpave specification $(20 \%)$. However, significant improvement of stripping resistance of local mixes was observed when P8 was used to modify the asphalt.

Table 6. Regression factors for fatigue test

\begin{tabular}{|c|c|c|c|c|c|c|c|c|}
\hline \multirow{3}{*}{$\begin{array}{l}\text { Asphalt } \\
\text { Mix Type }\end{array}$} & \multicolumn{4}{|c|}{ RT } & \multicolumn{4}{|c|}{ RY } \\
\hline & \multicolumn{2}{|c|}{$\begin{array}{c}\text { Regression } \\
\text { Factors } @ 25^{\circ} \mathrm{C}\end{array}$} & \multicolumn{2}{|c|}{$\begin{array}{c}\text { Regression } \\
\text { Factors } @ \mathbf{5 0}^{\circ} \mathrm{C}\end{array}$} & \multicolumn{2}{|c|}{$\begin{array}{c}\text { Regression } \\
\text { Factors } @ 25^{\circ} \mathrm{C}\end{array}$} & \multicolumn{2}{|c|}{$\begin{array}{c}\text { Regression } \\
\text { Factors } @ \mathbf{5 0}^{\circ} \mathbf{C}\end{array}$} \\
\hline & I & $\mathbf{S}$ & I & $\mathbf{S}$ & I & $\mathbf{S}$ & $\mathbf{I}$ & $\mathbf{S}$ \\
\hline Control & 9946.5 & -0.524 & 7924.9 & -0.626 & 806.3 & -0.261 & 920.8 & -0.247 \\
\hline P5 & 6890.9 & -0.464 & 3623.5 & -0.411 & 4032.8 & -0.362 & 1566.3 & -0.286 \\
\hline P6 & 7961.3 & -0.462 & 3514.0 & -0.398 & 36590.0 & -0.549 & 9489.1 & -0.451 \\
\hline P8 & 4384.3 & -0.365 & 1801.8 & -0.295 & 7012.5 & -0.429 & 5026.0 & -0.403 \\
\hline P9 & 9812.7 & -0.462 & 4079.9 & -0.393 & 562.5 & -0.202 & 920.7 & -0.286 \\
\hline
\end{tabular}


Abdul Wahhab and Abaker / The Journal of Engineering Research 1 (2004) 19-28

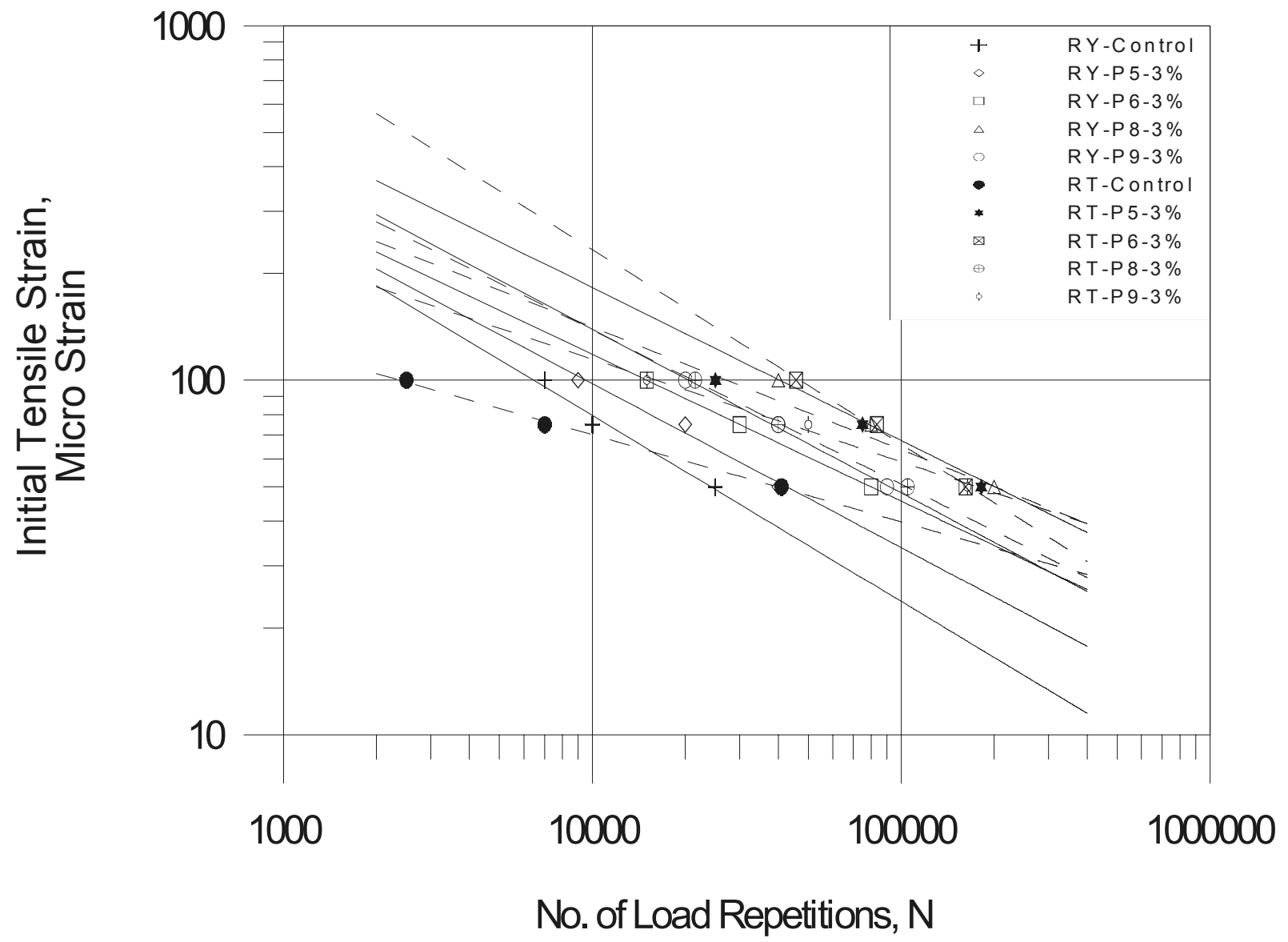

Figure 7. Fatigue curves for modified wearing course mixes at $25^{\circ} \mathrm{C}$

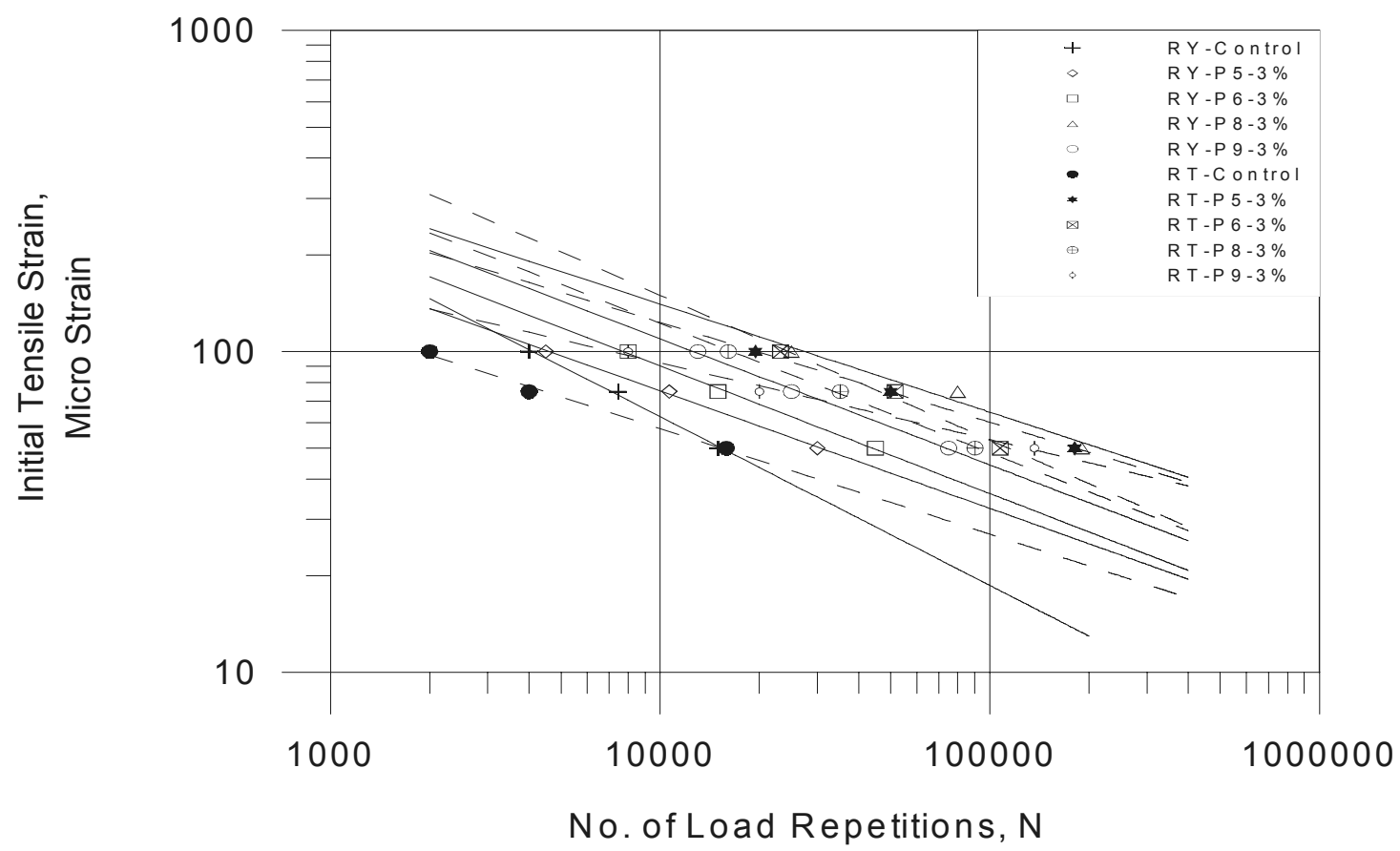

Figure 8. Fatigue curves for modified wearing course mixes at $50^{\circ} \mathrm{C}$ 


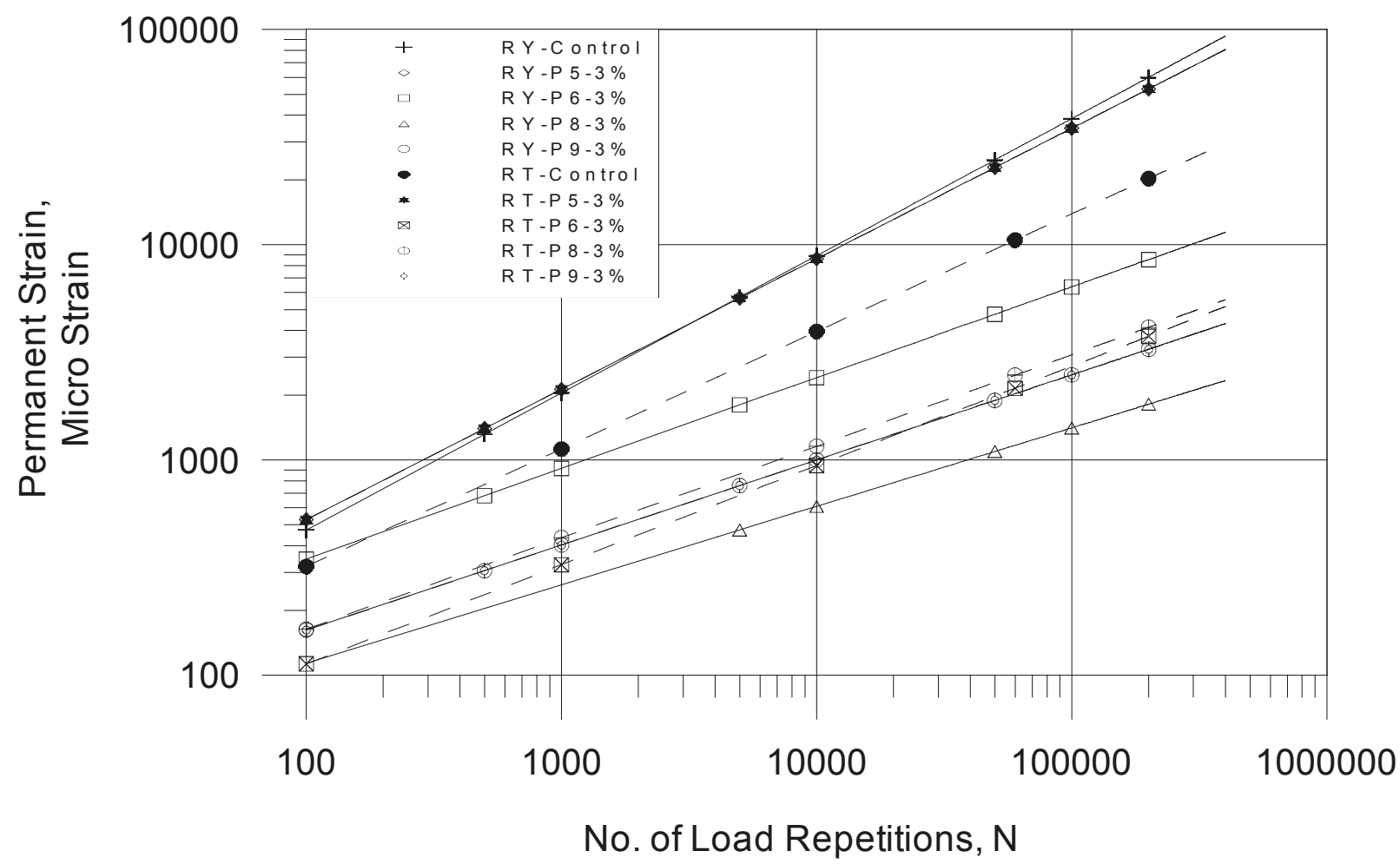

Figure 9. Rutting curves at 100-initial micro-strain $@ 25^{\circ} \mathrm{C}$

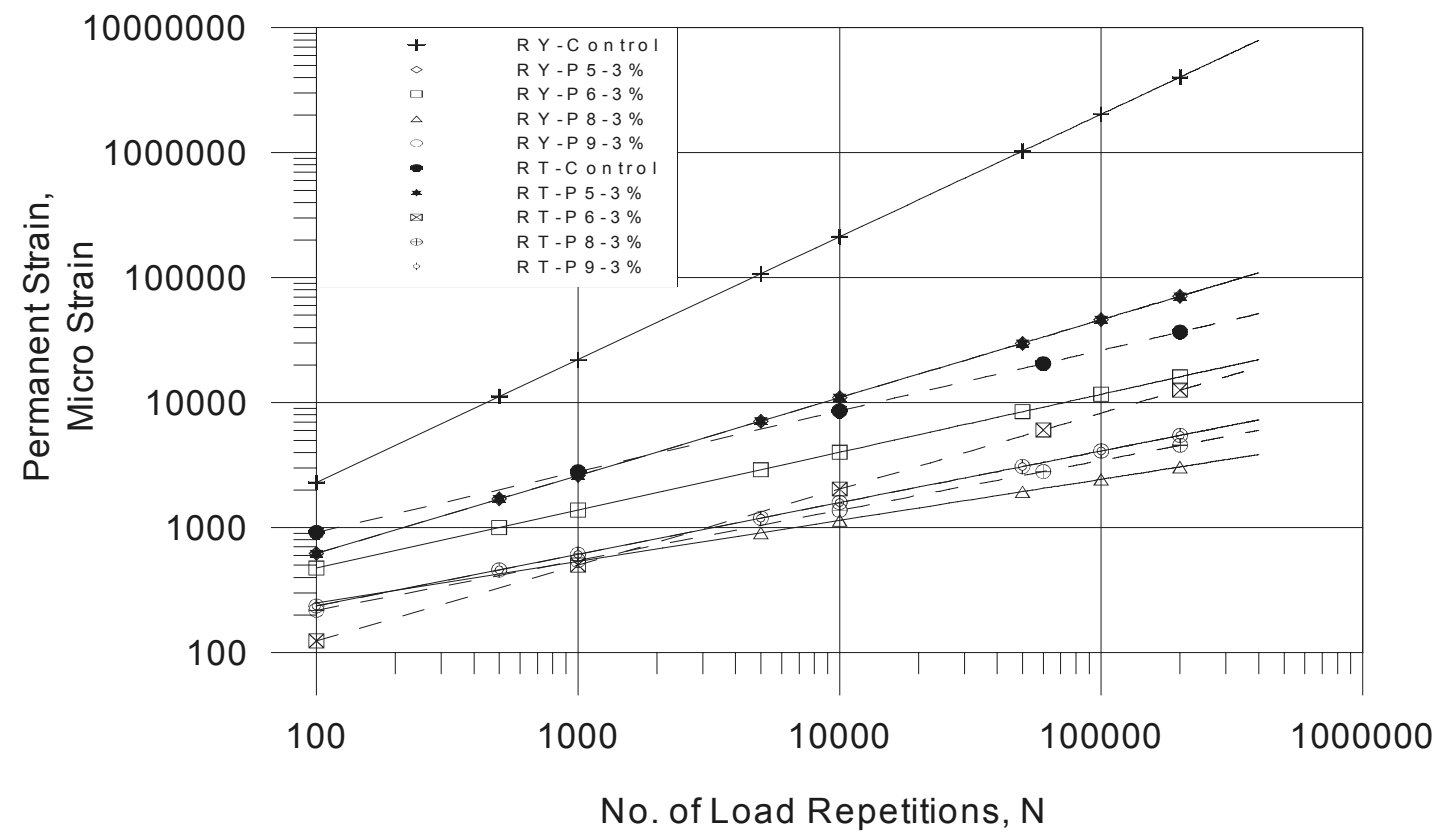

Figure 10. Rutting curves at 100-initial miro-strain $@ 5^{\circ} \mathrm{C}$ 
Generally, the ITS results of both RY and RT asphalt seem to be the same except when polymer type P9 is used. The percent loss in ITS of P9-RY is almost $50 \%$ of the percent loss of P9-RT. This indicates that P9 is somehow more effective when used with the RY asphalt.

Resilient modulus ( $M_{R}$ test ASTM D 4123): Resilience is a measure of pavement response in terms of repeated stresses and corresponding strains. Polymer-modified mixes showed an improved diametral resilient modulus compared to the control mix. The average resilient modulus at $25^{\circ} \mathrm{C}$ was found to be $547 \mathrm{ksi}(3782 \mathrm{MPa})$ for the control RY mix. This value increased to $800 \mathrm{ksi}$ for the P8 mix. The average resilient modulus at $50^{\circ} \mathrm{C}$ increased from $85 \mathrm{ksi}(587 \mathrm{MPa})$ for the control RY mix to $369 \mathrm{ksi}$ (2552 MPa) for P8 (Table 5, Figures 5 and 6). Although control RT mix had a low $M_{R}$ compared to the control RY mix, its blends with P5, P6, and P8 showed higher $M_{R}$ values compared to RY blends. This phenomenon may be linked to the way polymers are dispersed in the asphalt and the cross-linking between polymer molecules and asphalt molecules.

Fatigue performance: Diametral fatigue test results for wearing course mixes of the four polymer types (P5, P6, $\mathrm{P} 8$ and $\mathrm{P} 9$ in addition to the control mix) at testing temperatures of $25^{\circ} \mathrm{C}$ and $50^{\circ} \mathrm{C}$ are shown in Figures 7 and 8 for each polymer. Nine samples were tested for fatigue (three at each strain level). Linear regression analyses were done at each strain level. The results showed a normal linear relationship between the logarithm of applied initial tensile strain and the logarithm of fatigue life (number of applied load repetitions until failure). The fatigue data were analyzed by regression analysis to determine the fatigue relationship parameters in the following form:

$$
\varepsilon_{\mu}=1 *\left(N_{j}\right)^{s}
$$

where:

$\varepsilon_{t}=$ initial tensile strain,

$N_{f}=$ number of load repetitions to failure;

$I=$ anti-log of the intercept of the logarithmic relationship; and

$S=$ slope of the logarithmic relationship.

Regression parameters for Equation (1) are shown in Table 6 . The results obtained show significant improvement in fatigue life of the control specimen when modified with polymer, particularly at low strain and high temperature levels. P8 showed higher fatigue life (about 50 times higher than control mix) followed by P9, P6, and P5, respectively at both high and low temperatures.

Permanent deformation: Permanent deformation was simultaneously recorded during fatigue tests at $25^{\circ} \mathrm{C}$ and $50^{\circ} \mathrm{C}$, Figures 9 and 10 . The results indicated that a straight-line relationship exists between the logarithm of number of load repetitions and the logarithm of permanent strain. The permanent deformation properties were determined using :

$$
c_{2}-l *(N)^{3}
$$

$$
\begin{aligned}
\varepsilon_{p}= & \text { accumulated permanent strain; } \\
N= & \text { number of load repetitions; } \\
I= & \text { anti-log of the intercept of the logari- } \\
& \text { thmic relationship; and } \\
S= & \text { slope of the straight line of the log-log } \\
& \text { plot. }
\end{aligned}
$$

Parameters $I$ and $S$ were obtained using permanent deformation experimental data in a regression analysis. Results indicated that polymer modification reduced the permanent deformation potential of asphalt mixes when compared to the control mix. The improved rutting resistance was clear at low and high temperatures. P5 showed similar behavior to the control mix at $25^{\circ} \mathrm{C}$. The behavior became more elastic at $50^{\circ} \mathrm{C}, \mathrm{P} 8$ showed the best rutting performance followed by P9, P6, and P5, respectively.

\section{Conclusions}

The tested polymers were very effective in improving the rheological properties of the neat asphalt binders to meet and satisfy the performance requirements. Mixtures with MDPE, HDPE and HDPE (II) showed a significant increase in resilient modulus at both high and low temperatures compared to the control mixture. Modified asphalt mixtures showed a significant variation in their water susceptibility. Some mixtures were more sensitive than others. The average percentage loss in strength due to mois ture damage was reduced effectively by HDPE. The results showed significant improvement in fatigue behavior of all the polymer type mixes compared with the control mix. Mixes with HDPE showed higher fatigue life (about 50 times higher than the control mix) followed by HDPE-II, MDPE and LLDPE, respectively, at high and low temperatures for both types of asphalt. The results indicated that polymer modification resulted in a $20 \%$ reduction in permanent deformation compared to the control mix. The improved rutting resistance was clear at both low and high temperatures. Mixing with LLDPE showed similar behavior to the control mix at $25^{\circ} \mathrm{C}$, though the behavior was more elastic at $50^{\circ} \mathrm{C}$. Mixing with HDPE showed the best rutting performance followed by HDPEII, MDPE, and LLDPE, respectively.

\section{Acknowledgements}

The authors would like to acknowledge the support provided by King Fahd University of Petroleum \& Minerals (KFUPM) and Saudi Basic Industries Company (SABIC). 


\section{References}

A1-Abdul Wahhab, H., and Al-Amri, G., 1991, "Laboratory Evaluation of Reclaimed Rubber Asphaltic Concrete Mixes," ASCE Journal of Materials, 3 (3), pp. 189-203.

A1-Abdul Wahhab, H., Ali, F., Asi, I., and Al-Dhubeeb, I., 1996, "Adaptation of SHRP Performance Based Asphalt Specifications to the Gulf Countries," Final Report, King Abdulaziz City for Science and Technology (KACST), Riyadh.

Anderton, G.L., 1991, "Modified Asphalt Binders for Military Airfield Pavement," Proceedings, AAPT, Vol. 60.

Bahia, H., Hanson, D.I., Zeng, M., Zhai, H., Khatri, M., and Anderson, R. (2001), "Characterization of Modified Asphalt Binder in Superpave Mix Design," NCHRP Report 459, National Academy Press, Washington, D.C.

Baig, M..,, and Al-Abdul Wahhab, H., 1998, "Mechanistic Evaluation of Hedmanite and Lime Modified Asphalt Concrete Mixes," ASCE Journal of Materials, 10 (3), pp. 153-160.
Bouldin, M.G. et al., 1991, "Rheology and Microstructure of Polymer/Asphalt Blends," Journal of Rubber Chemistry and Technology, 67 (4).

Harrigan, E.T. et al. (Editor), 1994, "The SUPERPAVE Mix Design System Manual of Specifications, Test Methods, and Practices," SHRP-A-379, National Research Council, Washington, D.C.

Isacsson, U.,. and Lu, X., 1999, "Modified Asphalt Pavement Materials - The European Experience," Proceedings, AAPT, Vol. 68 p. 35.

Khattak, M.J., and Baladi, G.Y., 2001, "Paving Asphalt Polymer Blends: Relationships between Composition, Structure and Properties," TRB 10, No. 01-2813, 80th Transportation Research Board Annual Meeting, Washington, D.C.

Sartori, F., Bonemazzi, F., Bbraga, V., and Corrieri, R., 1996, "Characteristic of Polymers and Polymer Modified Binders," TRR No. 1535, Transportation Research Record, Washington, D.C.

Wegan, V., and Brule, B., 1999, "Polymer Modified Asphalt Cements Used in the Road Construction Industry," Proceedings, AAPT, Vol. 68, p. 64. 